\title{
circRNA circ_POLA2 increases microRNA-31 methylation to promote endometrial cancer cell proliferation
}

\author{
XIA FANG ${ }^{1}$, JINHUA WANG ${ }^{2}$, \\ LINGYING CHEN $^{1}$ and XIAOCHUN ZHANG ${ }^{1}$ \\ Departments of ${ }^{1}$ Gynecology and ${ }^{2}$ Neurology, Beilun District People's Hospital, Ningbo, Zhejiang 315800, P.R. China
}

Received December 29, 2020; Accepted June 24, 2021

DOI: $10.3892 / \mathrm{ol} .2021 .13023$

\begin{abstract}
Circular RNA (circRNA) circ_POLA2 is an oncogene in lung and cervical cancers. However, the role of circ_POLA2 in other types of cancer is unknown. The present study investigated the role of circ_POLA2 in endometrial cancer (EC). The mRNA expression levels of circ_POLA2 and microRNA (miR)-31 in EC and paired adjacent normal tissues were analyzed using reverse transcription-quantitative (RT-qPCR). Overexpression of circ_POLA2 was achieved in the EC cell lines, and its effects on miR-31 mRNA expression level and methylation were evaluated using RT-qPCR and methylation-specific PCR (MSP), respectively. Cell proliferation was assessed using a Cell Counting Kit-8 assay. The results indicated that circ_POLA 2 was highly expressed in EC tissue and inversely correlated with miR-31 mRNA expression level. MSP analysis showed that circ_POLA2 overexpression increased miR-31 methylation and RT-qPCR analysis showed that circ_POLA2 overexpression decreased miR-31 mRNA expression level. Furthermore, circ_POLA2 overexpression also increased EC cell proliferation, while miR-31 overexpression decreased cell proliferation. Finally, circ_POLA2 overexpression reduced the effects of miR-31 overexpression. In conclusion, circ_POLA2 may increase miR-31 methylation of miR-31 in EC cells to promote cancer cell proliferation.
\end{abstract}

Correspondence to: Dr Xia Fang or Dr Xiaochun Zhang, Department of Gynecology, Beilun District People's Hospital, 1288 Lushan East Road, Ningbo, Zhejiang 315800, P.R. China

E-mail: XiaFangZhejiang@163.com

E-mail: ui8275@163.com

Abbreviations: CCK-8, Cell Counting Kit-8; circRNA, circular RNA; Cq, threshold cycle; EC, endometrial cancer; MSP, methylation-specific PCR; NC, negative control; RT-qPCR, reverse transcription-quantitative PCR

Key words: circ_POLA2, miR-31, endometrial cancer, methylation, proliferation

\section{Introduction}

As the most common type of malignancy originating from the gynecological system in developed countries, endometrial cancer (EC) primarily affects women $>55$ years of age (1). EC accounted for $\sim 4.8 \%$ of all cases of cancer in women between 1999 and 2006 (2). With advances in the treatment of EC, $>95 \%$ of patients with localized tumors survive for 5 years following diagnosis (3-5). However, effective treatment for metastatic EC remains poor (6). In addition, distant tumor metastasis, such as rectal and bladder metastases, is common in patients with EC (6). Once tumors have spread to distant sites, $<17 \%$ of patients with EC survive for 5 years (3-5). Therefore, the development of novel approaches for EC treatment is required.

The main risk factors for EC include obesity, aging, diet, type 2 diabetes and a history of breast or ovarian cancer (7). However, the exact mechanisms underlying EC remain unclear. EC growth and metastasis, as well as the development of drug resistance in EC cells, involve molecular components (8-10). Progress in the elucidation of the molecular pathways involved in EC has resulted in the development of novel therapies that aim to treat EC by regulating the mRNA expression level of EC-related genes (8-10). However, effective targets for EC-targeted therapy are lacking. Circular RNAs (circRNAs) have either no or limited protein-coding capacity, but participate in human cancer by regulating transcription and translation $(11,12)$. Therefore, circRNAs may serve as potential targets for EC treatment. A previous study described a novel circRNA, circ_POLA2, with congenic functions in lung and cervical cancers $(13,14)$. Our previous study, using deep sequencing analysis revealed altered circ_POLA2 expression level in EC, with an inverse correlation with microRNA (miR)-31, which has also been associated with cancer biology (15). The present study aimed to investigate the mechanism of regulation in EC cell proliferation via miR-31.

\section{Materials and methods}

Tissue acquisition. Between April 2018 and April 2020, 60 patients with EC (all female; 26 cases at stage I or II and 34 cases at stage III or IV) were admitted to Beilun District People's Hospital (Zhejiang, China). Patients with recurrent EC were not enrolled into the present study. Patients receiving current treatment therapies were also excluded from the study, 
as were patients with other severe clinical complications, such as chronic renal or hepatic disease, chronic obstructive pulmonary disease, asthma and congenital diseases. The age range of the patients was 52-68 years, with a mean age of $60.7 \pm 5.5$ years. The present study was approved by the Ethics Committee of Beilun District People's Hospital (Zhejiang, China) and written informed consent was obtained from all patients. Before treatment, specimens of both EC and paired adjacent normal (within $5 \mathrm{~cm}$ around tumors) tissues were collected from each patient using fine-needle aspiration. Histopathological analysis was performed on all tissue specimens to confirm that the correct specimens were collected, according to the guidelines of the German Working Group on Gynecological Oncology (16). The tissue specimens were stored at $-80^{\circ} \mathrm{C}$ or in liquid nitrogen before the subsequent experiments. Association between miR-31 expression level and the clinicopathological parameters (age, sex, histopathological grade, depth of myometrial invasion, lymphatic metastasis and distant metastasis) in patients with EC are shown in Table I.

EC transfection. A total of two human EC cell lines, HEC-1-A and RL95-2 (both from American Type Culture Collection) were used as the EC cell models. Cell culture was cultured in RPMI-1640 medium (Gibco; Thermo Fisher Scientific, Inc.), supplemented with 10\% FBS (Invitrogen; Thermo Fisher Scientific, Inc.) at $37^{\circ} \mathrm{C}$ in a humidified incubator with $5 \% \mathrm{CO}_{2}$ according to the manufacturer's instructions. Subsequent assays were performed using cells at $\sim 85 \%$ confluence. The cells were transfected with miR-31 mimics and/or circ_POLA2 overexpression plasmid using Lipofectamine ${ }^{\circledR} 3000$ (Thermo Fisher Scientific, Inc.) according to the manufacturer's protocol. The cells were cultured as aforementioned for $48 \mathrm{~h}$ after transfection before subsequent experiments.

A backbone vector expressing circ_POLA2 was constructed using the pcDNA3.1(+) circRNA mini vector (Addgene, Inc.). The following primer sequences were used to construct circ_POLA2: forward, 5'-GGAATTCATGTCCGCATCCGC C-3' and reverse 5'-ATAAGAATTCAGATCCTGACGACC-3'. miR-31 mimics were synthesized by Shanghai GenePharma Co., Ltd., and negative control (NC; cat. no. miR1N0000001-1-5) miRNAs were purchased from Guangzhou RiboBio Co., Ltd. The sequence of the miR-31 mimics and NC miRNA are as follows: 5'-UAGCAGCACAGAAAUAUUGGC-3' and 5'-UUG UACUACACAAAAGUACUG-3', respectively. To overexpress circ_POLA2 and miR-31, the HEC-1-A and RL95-2 cells $\left(1 \times 10^{8}\right)$ were transfected with circ_POLA2 expression vector $(1 \mu \mathrm{g})$ or miR-31 mimics $(40 \mathrm{nM})$ using Lipofectamine ${ }^{\circledR} 2000$ reagent (Invitrogen; Thermo Fisher Scientific, Inc.). The same number of cells were transfected with empty vector or NC miR mimics using the same method as the overexpression vector and miR-31 mimics. Empty vector or untreated cells were used as the control (C) group. Subsequent assays were performed $48 \mathrm{~h}$ later.

Methylation-specific PCR (MSP). DNA was extracted from the HEC-1-A and RL95-2 cells transfected with circ_POLA2 overexpression plasmid using a Monarch ${ }^{\circledR}$ Genomic DNA Purification kit (New England Biolabs, Inc.). An EZ DNA Methylation kit (cat. no. D5001; Zymo Research Corp.) was used to convert the genomic DNA into bisulfite modified DNA. Firstly, MSP was performed to analyze miR-31 methylation, in which the DNA was modified by sodium bisulfite treatment to convert unmethylated cytosine to uracil, while methylated cytosine remained intact. Secondly, following the removal of bisulfite and completion of the chemical conversion, the modified DNA was used as the template for PCR using Taq DNA polymerase (Takara Bio, Inc.) The following primer sequences were used: Methylation forward, 5'-TTGTGTATAATTTGG GGCGTC-3' and reverse, 5'-CCAACTTACCTACGAATC CGA-3', and unmethylation forward, 5'-TTGTGTATAATT TGGGGTGTTGT-3' and reverse, 5'-CTCCCAACTTACCTA CAAATCCA-3'. The following thermocycling conditions were used: Initial denaturation at $95^{\circ} \mathrm{C}$ for $30 \mathrm{sec}$, then $55^{\circ} \mathrm{C}$ for $30 \mathrm{sec}, 72^{\circ} \mathrm{C} 30 \mathrm{sec}$. A total of 2 PCRs were performed for each DNA sample, one specific for originally methylated DNA without methylation for the gene of interest and one specific for originally unmethylated DNA with methylation. The PCR products were separated using a 6-8\% non-denaturing polyacrylamide gels and the bands were visualized by staining with ethidium bromide. The presence of a band of the appropriate molecular weight indicated the presence of unmethylated and/or methylated alleles in the original sample.

RNA extraction. Total RNA was isolated from the HEC-1-A and RL95-2 cells transfected with circ_POLA2 overexpression plasmid or miR-31 mimics, as well as paired tissue specimens from 60 patients with EC using RNAzol (Sigma-Aldrich; Merck KGaA). DNase I (Invitrogen; Thermo Fisher Scientific, Inc.) was used to remove the genomic DNA. RNA integrity was analyzed using agarose gel electrophoresis.

Reverse transcription-quantitative PCR (RT-qPCR). The cDNA samples were prepared using a Bio-Rad cDNA Supermix kit (Bio-Rad Laboratories, Inc.). The following temperature protocol was used for RT: Incubation at $50^{\circ} \mathrm{C}$ for $15 \mathrm{~min}$ then $75^{\circ} \mathrm{C}$ for $5 \mathrm{~min}$. The following housekeeping genes were used as the internal controls: GAPDH and U6. The expression level of mature miR-31 was determined using the All-in-One ${ }^{\mathrm{TM}}$ miRNA RT-qPCR Detection kit using SYBRGreen (GeneCopoeia, Inc.) following the manufacturer's instructions. For circ_POLA2, qPCR was performed using a LightCycler ${ }^{\circledR} 480$ SYBR Green I Master (Roche Diagnostics). The following thermocycling conditions were used for both miRNA and cir_POLA2: Initial denaturation at $95^{\circ} \mathrm{C}$ for $30 \mathrm{sec}$, then $95^{\circ} \mathrm{C}$ for $5 \mathrm{sec}, 60^{\circ} \mathrm{C} 34 \mathrm{sec}$ for 40 cycles; then $95^{\circ} \mathrm{C}$ for $15 \mathrm{sec}, 60^{\circ} \mathrm{C}$ for $1 \mathrm{~min}$ and $95^{\circ} \mathrm{C}$ for $15 \mathrm{sec}$. The threshold cycle $(\mathrm{Cq})$ values were analyzed using the $2^{-\Delta \Delta \mathrm{Cq}}$ method. Analysis of relative gene expression was performed using the $2^{-\Delta \Delta \mathrm{Cq}}$ method (17).

The following primer sequences were used: Circ POLA2 forward, 5'-ATGTCCGCATCCGCC-3' and reverse 5'-TCAGATCCTGACGACC-3'; GAPDH forward, 5'-GCA CCGTCAAGCTGAGAAC-3' and reverse 5'-GGTGAA GACGCCAGTGGA-3'; miR-31 forward, 5'-AGGCAAGAU GCUGGCAUAGCU-3' and reverse 5'-AAAGGCAAGAUG CUGGCAUAG-3'; and U6 forward, 5'-CTCGCTTCGGCA GCACA-3' and reverse 5'-ACGCTTCACGAATTTGCG TGTC-3'. 
Table I. Association between miR-31 expression level and the clinicopathological parameters in patients with endometrial carcinoma.

\begin{tabular}{|c|c|c|c|}
\hline Clinicopathological parameter & Number & miR-31 expression level ${ }^{a}$ & P-value \\
\hline Age, years & & & 0.059 \\
\hline$<60$ & 37 & $0.013(0.005-0.042)$ & \\
\hline$\geq 60$ & 23 & $0.156(0.068-0.450)$ & \\
\hline Stage & & & $0.0002^{\mathrm{b}}$ \\
\hline I & 16 & $0.123(0.051-0.279)$ & \\
\hline II & 10 & $0.008(0.006-0.021)$ & \\
\hline III/IV & 34 & $0.004(0.003-0.005)$ & \\
\hline Histopathological grade & & & $0.011^{\mathrm{b}}$ \\
\hline $\mathrm{G} 1$ and $\mathrm{G} 2$ & 30 & $0.120(0.045-0.251)$ & \\
\hline G3 & 20 & $0.116(0.006-0.743)$ & \\
\hline Depth of myometrial invasion & & & $0.0001^{\mathrm{b}}$ \\
\hline No infiltration & 20 & $0.342(0.130-0.632)$ & \\
\hline$\leq 1 / 2$ & 34 & $0.014(0.005-0.023)$ & \\
\hline$>1 / 2$ & 6 & $0.004(0.002-0.022)$ & \\
\hline Lymphatic metastasis & & & 0.431 \\
\hline Yes & 6 & $0.370(0.006-0.900)$ & \\
\hline No & 54 & $0.028(0.004-0.127)$ & \\
\hline Distant metastasis & & & $0.016^{\mathrm{b}}$ \\
\hline Yes & 2 & $0.178(0.126-0.262)$ & \\
\hline No & 58 & $0.025(0.005-0.226)$ & \\
\hline
\end{tabular}

${ }^{a}$ miR-31 expression level was calculated as the ratio between tumor and adjacent normal tissues and presented as the median (interquartile range). ${ }^{b} \mathrm{P}<0.05 . \mathrm{miR}$, microRNA.

Cell Counting Kit-8 (CCK-8) assay. CCK-8 assays were performed using a kit from Abcam (cat. no. ab228554). In a 96-well cell culture plate, 4,000 cells in $0.1 \mathrm{ml}$ fresh RPMI-1640 cell culture medium, supplemented with 10\% FBS were added. A total of 3 wells were used for each experiment. The cells were cultured at $37^{\circ} \mathrm{C}$. Cell proliferation was assessed by measuring the optical density at $450 \mathrm{~nm}$ at different time points $(0.5,1$ and $2 \mathrm{~h}$ ). The CCK-8 (Abcam) solution was added to each well to a final concentration of $10 \%, 2 \mathrm{~h}$ before the samples were measured.

Statistical analysis. The data were analyzed using GraphPad Prism v6 (GraphPad Software, Inc.). A total of 3 replicates were included in each experiment and the data in all figures are presented as the mean $\pm \mathrm{SD}$, while the data in Table $\mathrm{I}$ is presented as the median + IQR. Unpaired t-tests were used to compare 2 groups, while comparisons among multiple groups were performed using ANOVA followed by Tukey's post hoc test. Correlations were analyzed by linear regression. The mRNA expression levels of circ_POLA2 and miR-31 in EC and paired non-tumor tissues were compared using paired $\mathrm{t}$-tests. The association between the relative mRNA expression level of miR-31 and the clinicopathological data was analyzed using either a Mann Whitney U test or Kruskall-Wallis test for 2 or $>3$ groups, respectively. $\mathrm{P}<0.05$ was considered to indicate a statistically significant difference.

\section{Results}

circ_POLA2 and miR-31 expression level in EC tissues is altered. EC and paired adjacent normal tissue specimens were collected from 60 patients with EC. RT-qPCR was then performed to determine the mRNA expression levels of circ_POLA2 and miR-31. Compared with that in the adjacent normal tissues, circ_POLA2 was significantly upregulated in EC tissues (Fig. 1A). In addition, miR-31 was significantly downregulated in EC tissues compared with that in adjacent normal tissues (Fig. 1B). Therefore, circ_POLA2 and miR-31 may serve roles in EC. Furthermore, the association between the mRNA expression levels of miR-31 and certain clinicopathological parameters were also analyzed. The median tumor/normal tissue miR-31 expression ratio in EC was 0.034 in patients with a depth of myometrial invasion (18) of $\leq 1 / 2$ and 0.004 in patients with tumor invasion $>1 / 2$. The results also showed that the miR-31 expression level was associated with the clinical stage. The median tumor/normal tissue miR-31 expression ratio was 0.123 in 16 patients with stage I cancer and 0.004 in 34 patients with stage III/IV cancer. These results indicated an association between lower miR-31 mRNA expression levels and increasing stage and depth of tumor invasion. In addition, the median tumor/normal tissue miR-31 expression ratio was 0.120 in 30 patients with G1 and G2 histopathological grade and 0.116 in 20 patients with 
A

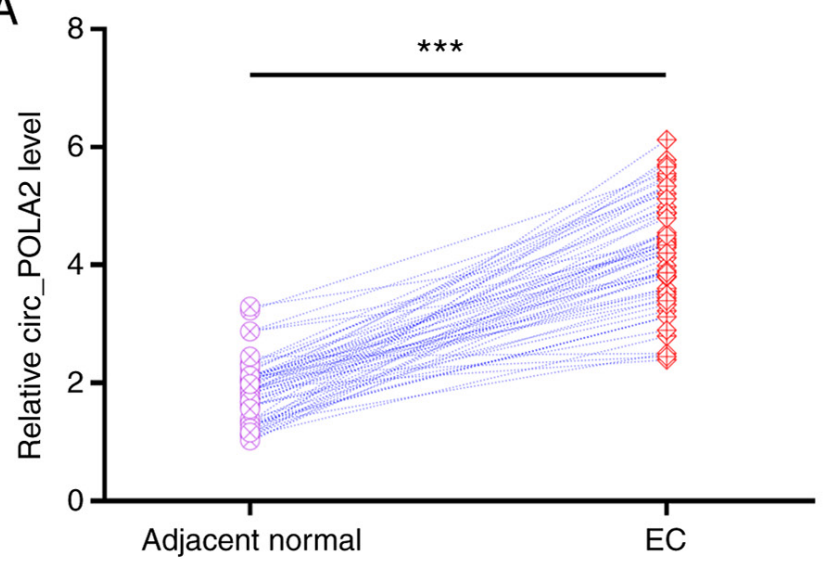

B

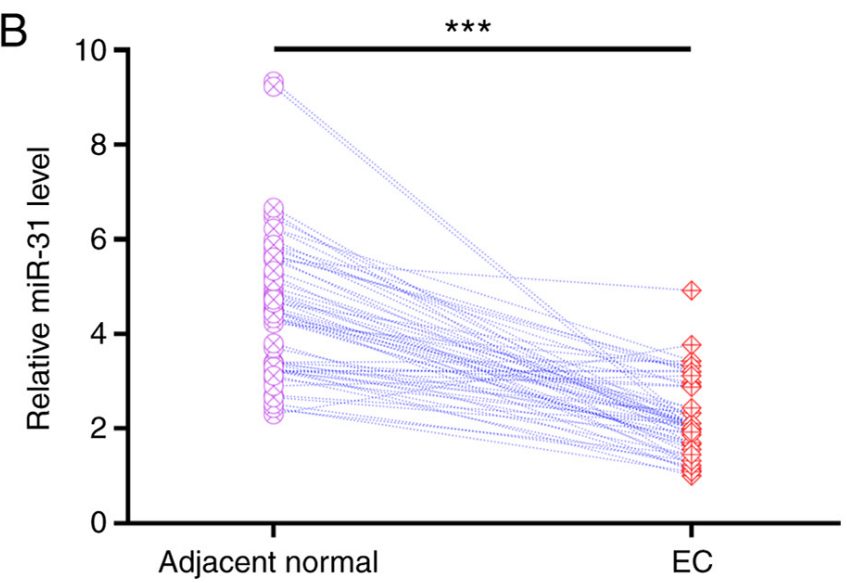

Figure 1. circ_POLA2 and miR-31 expression level is altered in EC tissues. EC and paired adjacent normal tissues were collected from 60 patients with EC. Reverse transcription-quantitative PCR was performed to determine (A) circ_POLA2 and (B) miR-31 mRNA expression level. The experiments were repeated three times and the data were presented as the mean $\pm \mathrm{SD} .{ }^{* * * *} \mathrm{P}<0.001$. EC, endometrial cancer; circ, circular RNA; miR, microRNA.
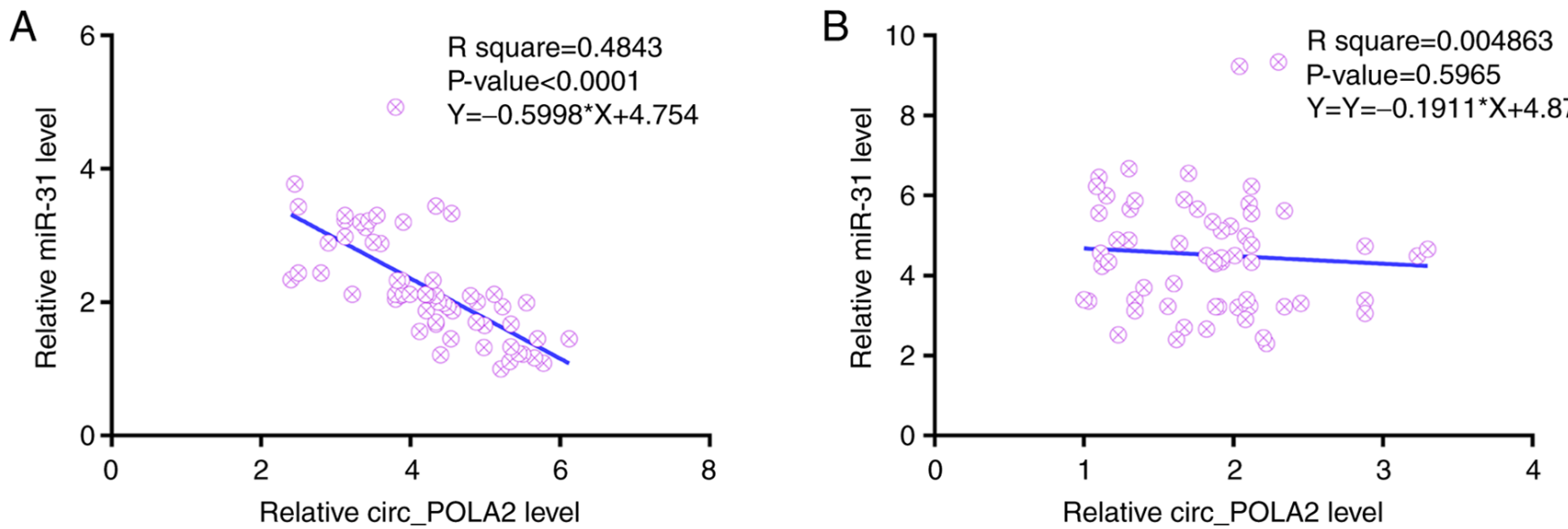

Figure 2. Correlation between circ_POLA2 and miR-31 mRNA expression levels. The correlations between circ_POLA2 and miR-31 in both (A) endometrial cancer and (B) adjacent normal tissues were analyzed using Pearson's correlation coefficient. circ, circular RNA; miR, microRNA.

G3 histopathological grade. The median tumor/normal tissue miR-31 expression ratio was 0.178 in 2 patients with distant metastasis and 0.025 in 58 patients without distant metastasis. These results indicated an association between lower miR-31 mRNA expression levels and increasing histopathological grade and no distant metastasis. miR-31 expression was not associated with other clinicopathological factors, such as patient age and lymphatic metastasis (Table I).

circ_POLA2 and miR-31 expression levels are correlated. Linear regression was performed to determine the correlation between circ_POLA2 and miR-31 expression levels in both EC (Fig. 2A) and adjacent normal (Fig. 2B) tissues. In EC tissue, circ_POLA2 mRNA expression level was inversely correlated with miR-31 mRNA expression level. However, their expression levels were not correlated in adjacent normal tissues. Therefore, circ_POLA2 and miR-31 may interact in EC.

circ_POLA2 overexpression decreases miR-31 expression levels in EC cell lines. circ_POLA2 and miR-31 were overexpressed in the HEC-1-A and RL95-2 cell lines (Fig. 3A). Overexpression of circ-POLA2 significantly decreased miR-31 mRNA expression level, compared with that in the empty vector group (Fig. 3B). However, miR-31 overexpression did not affect circ_POLA2 mRNA expression level, compared with that in the NC miRNA group (Fig. 3C). Therefore, circ_POLA2 may downregulate miR-31 expression level in the EC cell lines analyzed.

circ_POLA2 overexpression increases miR-31 methylation in the EC cell lines. To investigate the mechanism underlying the interaction between circ_POLA2 and miR-31, MSP was performed. The results showed increased methylation of the miR-31 gene in cells transfected with the circ_POLA2 expression vector (Fig. 4). Therefore, circ_POLA2 may downregulate miR-31 via methylation.

circ_POLA2 overexpression increases cell proliferation via $m i R-31$. The effects of circ_POLA 2 and miR-31 overexpression on the proliferation of the EC cell lines were 
A

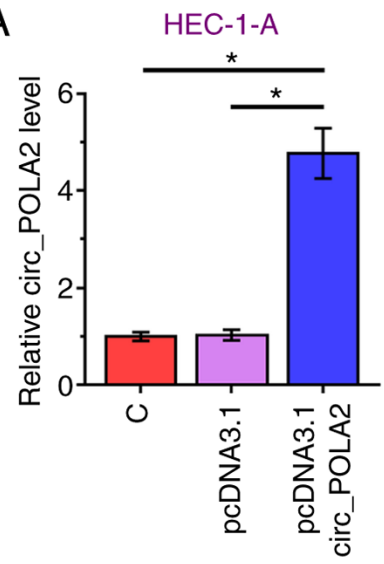

B

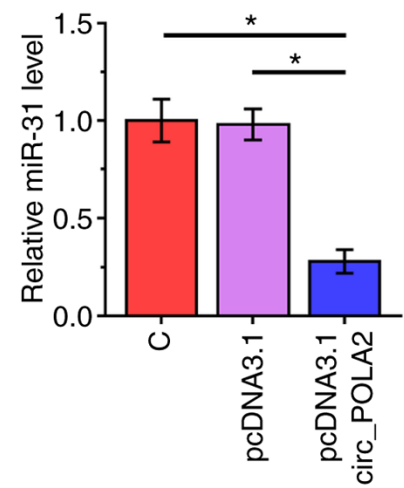

RL95-2

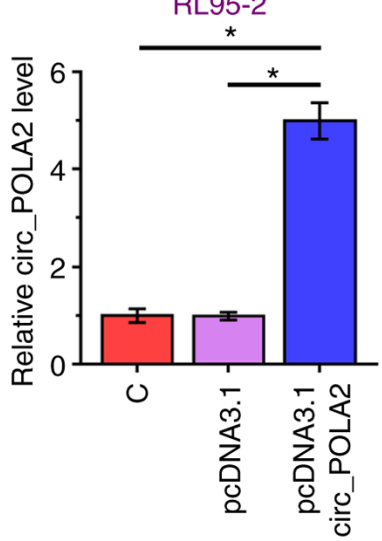

RL95-2

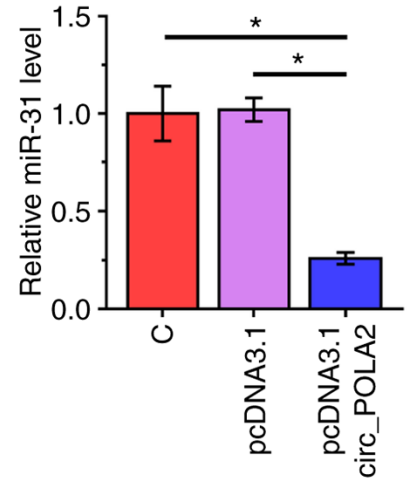

HEC-1-A

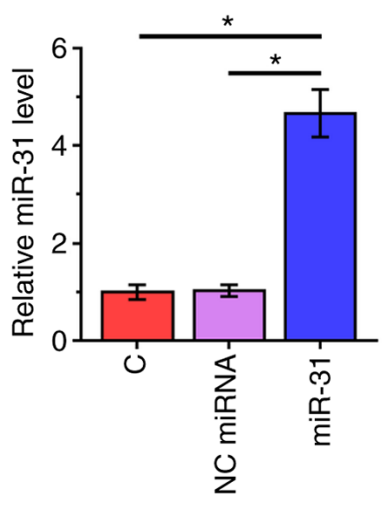

HEC-1-A

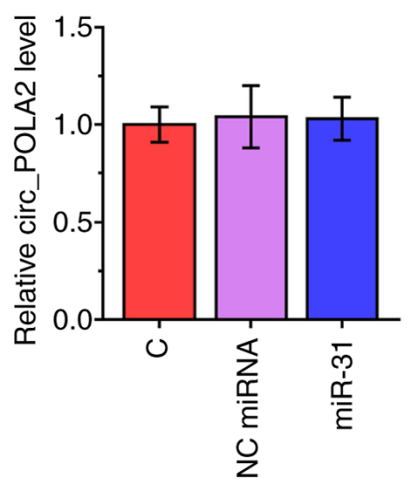

RL95-2

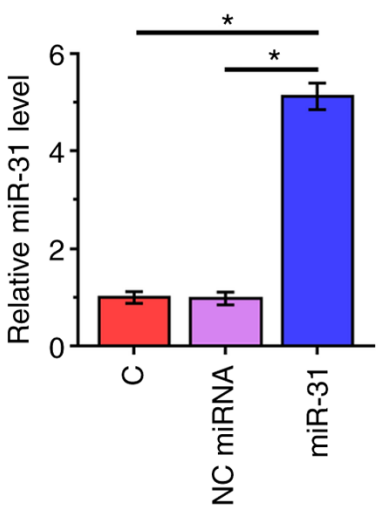

RL95-2

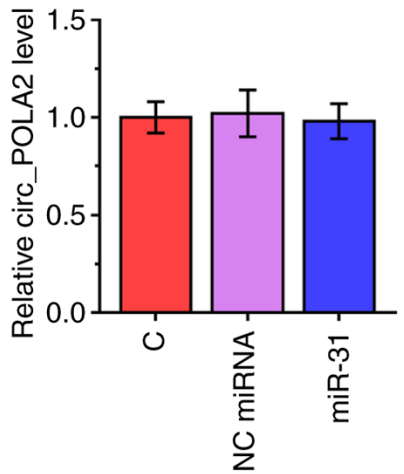

Figure 3. circ_POLA2 decreases miR-31 mRNA expression levels in the endometrial cancer cell lines. (A) circ_POLA2 and miR-31 were overexpressed in the HEC-1-A and RL95-2 cell lines. The effects of (B) circ-POLA2 overexpression on miR-31 mRNA expression level and (C) miR-31 overexpression on circ_POLA2 mRNA expression level were also analyzed. The experiments were repeated three times and the data were presented as the mean \pm SD. "P $<0.05$. C, control; circ, circular RNA; miR, microRNA; NC, negative control.

HEC-1-A

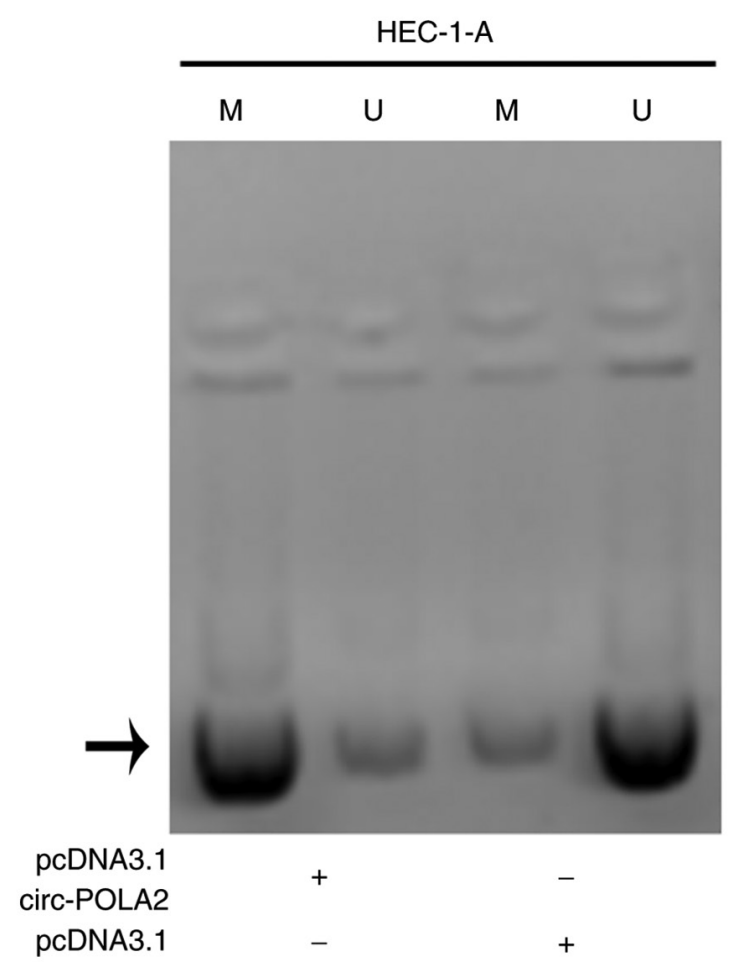

pcDNA3.1 circ-POLA2 pcDNA3.1

Figure 4. circ_POLA2 overexpression increases miR-31 methylation in the endometrial cancer cell lines. To investigate the mechanism underlying the interaction between circ_POLA2 and miR-31, methylation-specific PCR was performed to analyze the effects of circ_POLA2 overexpression on miR-31 methylation. Representative images of the 2 biological replicates are presented. $\mathrm{U}$, unmethylated; M, methylated; circ, circular RNA; miR, microRNA. 

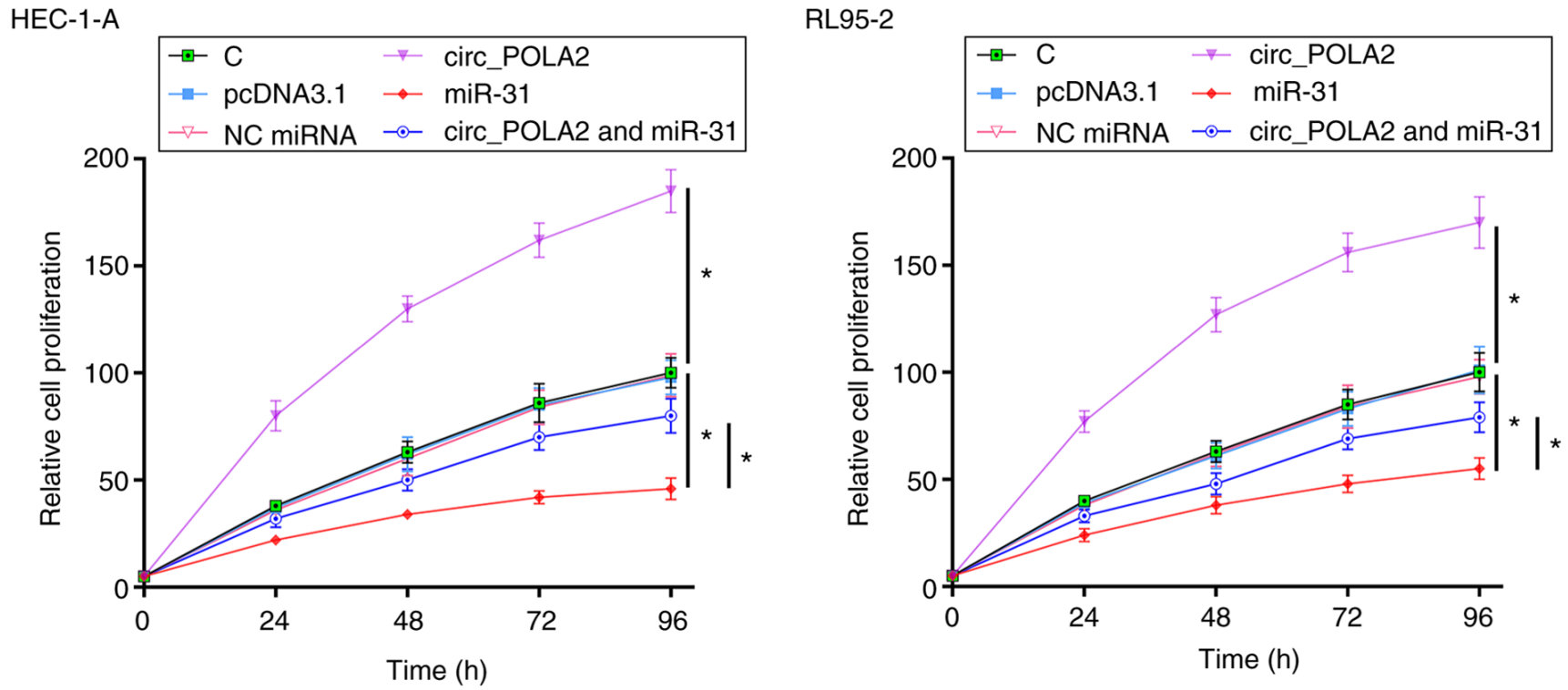

Figure 5. circ_POLA2 overexpression increases cell proliferation via miR-31. The effects of circ_POLA2 and miR-31 overexpression on the proliferation of the endometrial cancer cell lines were analyzed using Cell Counting Kit- 8 assays. The experiments were repeated three times and the data are presented as the mean $\pm \mathrm{SD}$. ${ }^{*} \mathrm{P}<0.05$. C, control; circ, circular RNA; miR, microRNA; NC, negative control.

evaluated using CCK-8 assays. circ_POLA2 overexpression increased EC cell proliferation, whereas miR-31 overexpression decreased cell proliferation compared with that in the empty vector group and NC miRNA, respectively. In addition, circ_POLA2 overexpression suppressed the effect of miR-31, compared with that in the miR-31 overexpression group (Fig. 5).

\section{Discussion}

The present study investigated the interaction between the expression levels of circ_POLA2 and miR-31 in EC. It was found that circ_POLA2 mRNA expression level was increased in EC tissues, and following further analysis using miR-31 mimics and circ_POLA2 overexpression in 2 EC cell lines, circ_POLA2 may suppress miR-31 expression via methylation to promote EC cell proliferation.

There have been two recent studies identifying circ POLA2 as an oncogenic circRNA in lung and cervical cancers $(13,14)$.circ_POLA2 was upregulated in lung cancer and it may interact with the miR-326/GNB1 axis to increase cancer cell stemness (13). Moreover, circ_POLA2 upregulation in cervical cancer, as well as its interaction with the miR-326/GNB1 axis to promote cancer progression (14). To the best of our knowledge, the present study is the first to report circ_POLA2 upregulation in EC tissues. In addition, circ_POLA 2 overexpression increased proliferation in the two EC cell lines. Therefore, circ_POLA2 may serve an oncogenic role in EC by promoting cancer cell proliferation.

miR-31 serves different roles in different types of cancer $(15,19)$. miR-31 was downregulated in gastric cancer, in which its low expression levels predicted poor patient overall survival time, suggesting its role as a tumor suppressor (15). By contrast, miR-31 was upregulated in cervical cancer and promoted cancer cell invasion, migration and proliferation (19). Mitamura et al (20) previously reported miR-31 upregulation in EC cell lines, in which it suppressed the Hippo tumor suppressor pathway to promote cancer development. By contrast, the present study observed miR-31 downregulation in EC tissues and its inhibitory effects on EC cell proliferation following increased expression in EC cell lines, suggesting a tumor-suppressing role. These contradictory observations may be explained by the fact that in the study by Mitamura et al (20) miR-31 mRNA expression level was only analyzed in EC cell lines, while in the present study the expression of miR-31 was analyzed in patients with EC. Additional studies are required to further elucidate the function of miR-31 in EC.

In addition to regulating gene transcription and translation, circRNAs may also act as miRNA sponges to exert functions in cancer biology $(11,12)$. In lung and cervical cancers, circ_POLA2 sponged miR-326 to promote cancer development $(13,14)$. The results of the present study indicated that circ_POLA2 downregulated miR-31 mRNA expression level in the EC cell lines via methylation. These results improved understanding of the interactions between circ POLA2 and miRNAs. However, the underlying mechanisms remain unclear. It was found that circ_POLA2 and miR-31 were not correlated in adjacent normal tissues, suggesting an indirect interaction between them. Future studies will utilize new experimental approaches, for example, using circRNA sequencing or microarrays to investigate the function and mechanism of circ-POLA and miRNAs in EC, and its expression distribution in EC cell lines (21).

In conclusion, the present study demonstrated that circ_POLA2 was upregulated in EC tissues and may downregulate miR-31 via methylation to promote cancer cell proliferation.

\section{Acknowledgements}

Not applicable. 


\section{Funding}

No funding was received.

\section{Availability of data and materials}

The datasets used and/or analyzed during the current study are available from the corresponding author on reasonable request.

\section{Authors' contributions}

$\mathrm{XF}$ and $\mathrm{XZ}$ designed the study. XF and JW performed the experiments. LC analyzed the data. XF wrote the manuscript. All authors read and approved the final version of manuscript. $\mathrm{XF}, \mathrm{XZ}, \mathrm{JW}$ and XF confirm the authenticity of all the raw data.

\section{Ethics approval and consent to participate}

The present study was approved by the Ethics Committee of Beilun District People's Hospital and written informed consent was obtained from all patients.

\section{Patient consent for publication}

Not applicable.

\section{Competing interests}

The authors declare that they have no competing interests.

\section{References}

1. Morice P, Leary A, Creutzberg C, Abu-Rustum N and Darai E: Endometrial cancer. Lancet 387: 1094-1108, 2016.

2. Duong LM, Wilson RJ, Ajani UA, Singh SD and Eheman CR Trends in endometrial cancer incidence rates in the United States, 1999-2006. J Womens Health (Larchmt) 20: 1157-1163, 2011.

3. Donkers H, Bekkers R, Massuger L and Galaal K: Systematic review on socioeconomic deprivation and survival in endometrial cancer. Cancer Causes Control 30: 1013-1022, 2019.

4. Sanni OB, Mc Menamin ÚC, Cardwell CR, Sharp L, Murray LJ and Coleman HG: Commonly used medications and endometrial cancer survival: A population-based cohort study. $\mathrm{Br}$ J Cancer 117: 432-438, 2017.

5. Morrison J: Endometrial cancer follow up; finding the confidence to let go?. BJOG 125: 1715, 2018.
6. Makker V, Green AK, Wenham RM, Mutch D, Davidson B and Miller DS: New therapies for advanced, recurrent, and metastatic endometrial cancers. Gynecol Oncol Res Pract 4: 19, 2017.

7. Busch EL, Crous-Bou M, Prescott J, Chen MM, Downing MJ, Rosner BA, Mutter GL and De Vivo I: Endometrial cancer risk factors, hormone receptors, and mortality prediction. Cancer Epidemiol Biomarkers Prev 26: 727-735, 2017.

8. Mitamura T, Dong P, Ihira K, Kudo M and Watari $\mathrm{H}$ : Molecular-targeted therapies and precision medicine for endometrial cancer. Jpn J Clin Oncol 49: 108-120, 2019.

9. Remmerie M and Janssens V: PP2A: A promising biomarker and therapeutic target in endometrial cancer. Front Oncol 9: 462, 2019.

10. Kunitomi H, Kobayashi Y, Wu RC, Takeda T, Tominaga E, Banno K and Aoki D: LAMC1 is a prognostic factor and a potential therapeutic target in endometrial cancer. J Gynecol Oncol 31: e11, 2020.

11. Shang Q, Yang Z, Jia R and Ge S: The novel roles of circRNAs in human cancer. Mol Cancer 18: 6, 2019.

12. Yu T, Wang $Y$, Fan $Y$, Fang $N$, Wang $T$, $X u T$ and Shu $Y$ : CircRNAs in cancer metabolism: A review. J Hematol Oncol 12: 90, 2019.

13. Fan Z, Bai Y, Zhang Q and Qian P: CircRNA circ_POLA2 promotes lung cancer cell stemness via regulating the miR-326/GNB1 axis. Environ Toxicol 35: 1146-1156, 2020.

14. Cao Y, Li J, Jia Y, Zhang R and Shi H: CircRNA circ_POLA2 promotes cervical squamous cell carcinoma progression via regulating miR-326/GNB1. Front Oncol 10: 959, 2020.

15. Zhang Y, Guo J, Li D, Xiao B, Miao Y, Jiang Z and Zhuo H: Down-regulation of miR-31 expression in gastric cancer tissues and its clinical significance. Med Oncol 27: 685-689, 2010.

16. Raffone A, Travaglino A, Mascolo M, Carotenuto C, Guida M, Mollo A, Insabato L and Zullo F: Histopathological characterization of ProMisE molecular groups of endometrial cancer. Gynecol Oncol 157: 252-259, 2020.

17. Livak KJ and Schmittgen TD: Analysis of relative gene expression data using real-time quantitative PCR and the 2(-Delta Delta C(T)) Method. Methods 25: 402-408, 2001.

18. Takeuchi M, Matsuzaki K and Harada M: Evaluating myometrial invasion in endometrial cancer: Comparison of reduced field-of-view diffusion-weighted imaging and dynamic contrast-enhanced MR imaging. Magn Reson Med Sci 17: 28-34, 2018.

19. Zheng W, Liu Z, Zhang W and Hu X: MiR-31 functions as an oncogene in cervical cancer. Arch Gynecol Obstet 292: 1083-1089, 2015.

20. Mitamura T, Watari H, Wang L, Kanno H, Kitagawa M, Hassan MK, Kimura T, Tanino M, Nishihara H, Tanaka S and Sakuragi N: MicroRNA 31 functions as an endometrial cancer oncogene by suppressing Hippo tumor suppressor pathway. Mol Cancer 13: 97, 2014

21. Ye F, Tang QL, Ma F, Cai L, Chen M, Ran XX, Wang XY and Jiang XF: Analysis of the circular RNA transcriptome in the grade 3 endometrial cancer. Cancer Manag Res 11: 6215-6227, 2019. International (CC BY-NC-ND 4.0) License. 